\title{
Um Ano do Retorno ao Sistema de Madri
}

\section{A Year of Return to the Madrid System}

\author{
Vanessa Pereira Oliveira Soares ${ }^{1}$ \\ Ricardo Sant'Anna Ramalho ${ }^{1}$ \\ Genizia Islabão de Islabão ${ }^{1}$ \\ ${ }^{1}$ Instituto Federal de Educação, Ciência e Tecnologia do Rio Grande do Sul, Porto Alegre, RS, Brasil
}

\begin{abstract}
Resumo
O presente artigo tem como objetivo apontar as dificuldades apresentadas pelo Acordo de Madri, as soluções trazidas pelo Protocolo de Madri e a diferença entre ambos, formadores do Sistema de Madri, que rege o registro internacional de marcas. Além disso, pretende-se expor as adequações pelas quais o Instituto Nacional da Propriedade Industrial necessitou passar para a adesão do país ao Protocolo de Madri com relação ao registro de marcas internacionais.
\end{abstract}

Palavras-chave: Marcas Internacionais. Registro Internacional. Protocolo de Madri.

\begin{abstract}
The purpose of this article is to present the difficulties presented by the Madrid Agreement, the solutions brought by the Madrid Protocol and the difference between both, forming the System of Madrid that governs the international registration of trademarks, in addition to exposing the adaptations by which the Institute National Industrial Property Law needed to pass for the country's adhesion to the Madrid Protocol for the registration of international trademarks.
\end{abstract}

Keywords: International trademarks. International registration. Protocol of Madrid.

Área Tecnológica: Propriedade Intelectual. Transferência de Tecnologia.

\section{Introdução}

Uma marca é um sinal que serve para identificar um produto ou um serviço, diferenciando-o de outros produtos e serviços de origem diversa. Quando se fala em sinal, nos referimos a uma espécie de nome, denominação, elemento que busca individualizar, tornar único. Quem cria uma marca para um produto ou serviço tem o propósito de denominar os frutos de sua atividade. Há, portanto, uma "rotulagem" da experiência oferecida ao mercado, que se apresenta como um ponto de referência definido para o cliente que deseja reviver as sensações experimentadas. Marca é o instrumento de retenção de clientes e de fidelização. No Brasil, a proteção das marcas se dá por meio do pedido de registro junto à autarquia federal Instituto Nacional da Propriedade Industrial (INPI). 
A proteção de marcas na seara internacional é amplamente abordada por meio do Acordo de Madri e do Protocolo de Madri. O Acordo de Madri, referente ao registro internacional de Marcas, foi originalmente assinado em 1891. Tal acordo foi internalizado pelo Brasil pela Lei n. 376/1896 e pelo Decreto n. 2.380/1896 que se referem a quatro protocolos firmados conjuntamente, entre eles o Acordo de Madri relacionado ao registro internacional de marcas (BRUCH; COPETTI, 2010). Em 1929, mediante assinatura do Presidente Washington Luís no Decreto n. 5.685/1929, o Brasil aderiu ao Acordo de Madri sobre o registro internacional de marcas (BRASIL, 1929). A vigência do Decreto, contudo, foi curta, pois o Brasil denunciou e revogou o Acordo por meio do Decreto n. 196/1934, assinado pelo Presidente Getúlio Vargas (BARBOSA, 2018; BRASIL, 1934). A decisão se deu para indicar um "bairrismo" na época e pelo favoritismo ao comércio brasileiro mediante a pressão de produtores e de comerciantes nacionais. Desde então, aquele que no Brasil tivesse o interesse de exportar seus produtos ou serviços e proteger sua marca internacionalmente teria que pedir o registro individualmente em cada país de interesse. O Protocolo de Madri foi firmado em 1991, tendo entrado em vigor tão somente em 1996. Esse tratado, também conhecido por Sistema de Madri, foi criado com o objetivo de tornar o registro de marcas internacionais mais atrativo para os países signatários da Convenção da União de Paris, uma vez que somente estes poderiam aderir e, consequentemente, usufruir dos benefícios advindos do Sistema de Madri.

Em julho de 2019, o Brasil deu um importante passo com o depósito junto à Organização Mundial da Propriedade Intelectual (OMPI) do instrumento de adesão ao Protocolo de Madri e, em 2 de outubro de 2019, o acordo foi ratificado com a publicação do Decreto n. 10.033/2019, que promulgou o tratado (BRASIL, 2019), permitindo o início da utilização no Brasil, regulamentado pela Resolução INPI/PR n. 247/2019.

Diante do exposto, ressalta-se que este artigo pretende trazer uma reflexão sobre como o Protocolo de Madri tem modificado o sistema de registro de marcas internacionais no Brasil.

\section{Metodologia}

O presente artigo tem como objetivo analisar quais foram as modificações sofridas pelo sistema brasileiro para registro de marcas diante da adesão ao Protocolo de Madri para registros de marcas internacionais. O artigo desenvolve uma pesquisa documental com abordagem qualitativa e indutiva, sendo assim, os dados analisados foram a legislação brasileira sobre registro de marcas e Propriedade Intelectual e também a doutrina sobre o Acordo e o Protocolo de Madri.

Com isso, pretende-se compreender os fenômenos advindos da nova sistemática de registros de marcas internacionais no Brasil como forma de estabelecer as relações entre si $e$ o cenário remanescente, além de aprofundar a exploração dos fenômenos do Protocolo de Madri, alicerçado em um processo de pesquisa, tanto bibliográfico como de legislações aplicáveis, consubstanciado no estudo histórico da adesão do Brasil ao tratado. 


\section{Resultados e Discussão: Acordo de Madri X Protocolo de Madri}

Em 14 de abril de 1891, durante uma das revisões da Convenção da União de Paris (COPETTI, 2008), na cidade de Madri, foi celebrado o acordo denominado "Acordo de Madri", que tinha como cerne o Acordo referente ao registro internacional de marcas de indústria e de comércio, sendo posteriormente incluídas as marcas de serviço e o Acordo referente às falsas indicações de procedência (DI BLASI, 2010).

O acordo passou por diversas revisões em Bruxelas (1900), Washington (1911), Haia (1925), Londres (1934), Nice (1957), Estocolmo (1967) e Genebra (1979) para determinar que as marcas devem ser registradas junto à repartição internacional da Organização Mundial da Propriedade Intelectual (OMPI), sediada em Genebra na Suíça. Os registros efetivados sob o pálio desse acordo serão considerados internacionais, possuindo validade em todos os países-membros do referido acordo (DI BLASI, 2010).

Para se utilizar das benesses do acordo, o requerente do registro deve ser pessoa física ou jurídica com nacionalidade, estabelecimento comercial/industrial real e efetivo ou ainda com domicílio em algum dos países membros. A marca é então registrada inicialmente no escritório nacional do país para em seguida ser solicitada a extensão internacional da proteção via OMPI. O pedido de registro internacional é publicado na Gazeta da OMPI, sendo comunicado aos países-membros o interesse por aquele registro. Cada um dos países então declara, com a devida fundamentação, dentro de um ano se poderá ou não conceder a proteção dentro de seu território. Se o parecer é positivo, o registro internacional surte efeito como o registro nacional. Se negativo, o pedido de registro terá o curso do processo de acordo com a legislação do país, cabendo ao solicitante da marca as ações devidas contra a negativa de registro (se cabível, a interposição de recurso) (DI BLASI, 2010).

Houve diversos conflitos de aceitação e de aplicabilidade do Acordo de Madri, implicando a rejeição da norma em diversos países. Um dos problemas atrelados ao Acordo de Madri é a dependência do registro nacional, ou seja, uma das condições para o deferimento do pedido de registro internacional é que o registro tenha sido concedido em sua origem. Assim, enquanto o registro não é analisado e concedido na via nacional, o procedimento não tem seu andamento na via internacional. De igual forma, o registro internacional permanece dependente do registro nacional pelo prazo de cinco anos. Assim, caso a marca tenha sua validade anulada junto ao país de origem, a marca internacional também será invalidada em todos os países nos quais houve o registro (DI BLASI, 2010). O acordo também estabelece um curto prazo de 12 meses para que os escritórios nacionais analisem os pedidos internacionais e a utilização do idioma francês como único usado para comunicações da secretaria internacional com os escritórios nacionais (MESQUITA, 2016).

No Brasil, o Acordo de Madri foi aprovado por meio do Decreto n. 5.685/1.929 e revogado quanto ao registro de marcas internacionais cinco anos depois pelo Decreto n. 196/1934 fundamentado no fato de que as classes produtoras eram contrárias à manutenção do registro, tendo se constatado por parte de consulta realizada junto aos órgãos técnicos que sua continuidade poderia prejudicar os interesses nacionais (DI BLASI, 2010). 
Barbosa (2008 apud BARBOSA, 2018, p. 11) afirma que, na revista de Direito Industrial de 1935, o Dr. Francisco Antônio Coelho, então Diretor Geral do Departamento Nacional da Propriedade Industrial, publicou artigo sob o título "A denúncia do Acordo de Madri". Nesse artigo, Barbosa (2008 apud BARBOSA, 2018, p. 13) destaca tal decisão como patriótica, resultado "[...] de uma campanha há longos anos sustentada pelos órgãos mais representativos das nossas classes conservadoras, notadamente as Associações Comerciais do Rio de Janeiro e de São Paulo". Isso se devia

[...] à necessidade de interromper o registro automático das marcas internacionais que, em virtude do citado Acordo, eram encaminhadas pelo Bureau Internacional de Berna, serviço esse que, além dos ônus administrativos, tantos prejuízos vinha causando aos nossos industriais e comerciantes. (BARBOSA, 2008 apud BARBOSA, 2018, p. 13)

Mais adiante, acrescenta:

Aliás, esse serviço, devido à falta de elementos necessários, sempre foi muito precário e era motivo de constantes reclamações que somente uma organização dispendiosa poderia evitar. Isso, porém, não se justificaria, tanto pelas exíguas vantagens auferidas como à imperiosa necessidade de restringir as despesas públicas. (BARBOSA, 2008 apud BARBOSA, 2018, p. 13)

E justifica:

Era impossível, porém, continuar indiferente às queixas dos nossos industriais e comerciantes a cujos sinais distintivos se negava a proteção legal, sob o fundamento de imitarem marcas internacionais destinadas a produtos ou artigos que inúmeras vezes, são totalmente desconhecidos e não tem curso nos nossos mercados. (BARBOSA, 2008 apud BARBOSA, 2018, p. 13).

O objetivo do Protocolo de Madri seria oferecer ao proprietário de uma marca a possibilidade de protegê-la automaticamente em vários países, membros desse protocolo, mediante um único depósito diretamente no escritório nacional ou regional de cada país ou grupo de países. Esse registro internacional teria os mesmos efeitos que o registro nacional efetuado em cada um dos países. Tal mecanismo, a princípio, facilitaria a manutenção da marca registrada $e$ unificaria os custos com a tramitação administrativa dessa marca. Ocorre que esses benefícios não são encontrados nos países cujo número de marcas nacionais é muito inferior ao número de marcas internacionais. Os países em desenvolvimento e subdesenvolvidos pagariam um alto custo para internacionalizar seu sistema marcário, e os escritórios desses países precisariam, antes de aderir a tal tratado, se estruturar para comportar tal sistema.

Nas primeiras sete décadas da existência do Acordo de Madri (WIPO, 2019), os registros internacionais, que eram apenas 76 em 1893, aumentaram gradualmente para pouco mais de 11.000 em 1959. Nos 30 anos seguintes, o número de registros permaneceu abaixo de 15.000, contudo, com o Protocolo de Madri em 1989, houve um rápido aumento no número de registros, chegando em 20.000 em 1998 e triplicando para mais de 60.000 em 2018.

A Figura1 demonstra como ocorreu o crescimento dos registros internacionais entre 1893 e 2018. 
Figura 1 - Direção de crescimento de registros internacionais via Acordo/Protocolo de Madri, 18932018

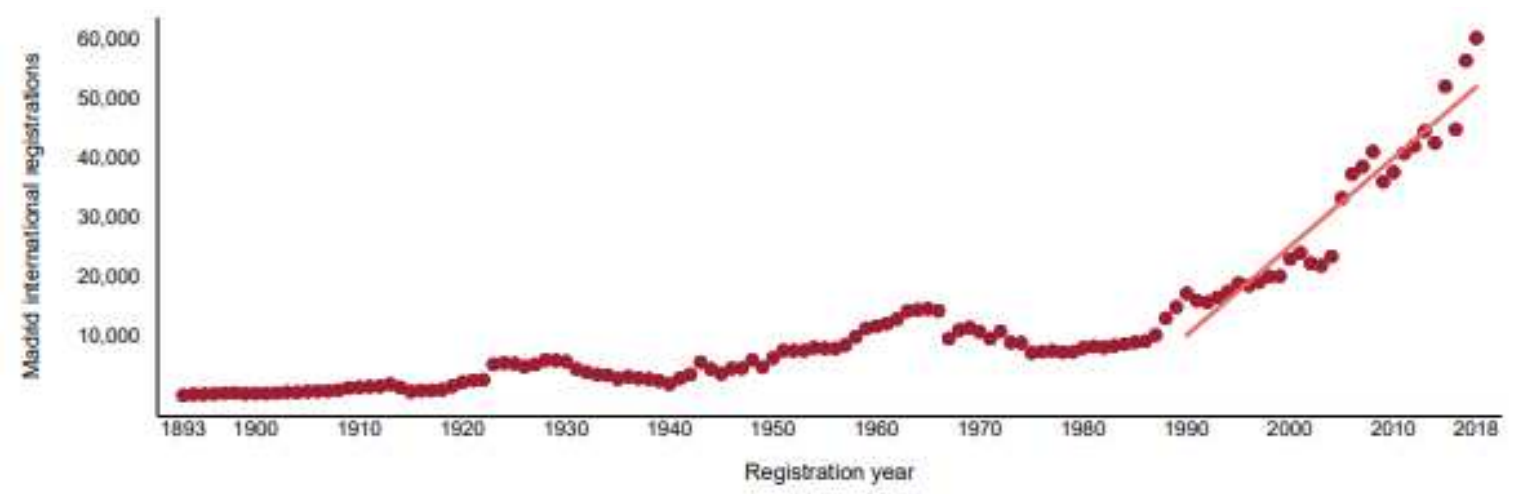

I MADRID REGISTRATIONS

Fonte: WIPO (2019)

Com o objetivo de dar agilidade e praticidade ao registro internacional de marcas, além de aperfeiçoar os procedimentos para obtenção de um registro internacional de marcas, alcançando uma maior parcela de países, firmou-se em 27 de junho de 1989 o Protocolo do Acordo de Madri (DI BLASI, 2010; MESQUITA, 2016), que entrou em vigor em 1996 (ARRABAL; COLOMBO, 2018), permitindo, então, o registro com base apenas no pedido de registro do país de origem (DI BLASI, 2010). O Sistema de Madri buscou resolver alguns obstáculos tidos como motivações para a não adesão ao Acordo de Madri, facilitando alguns impasses enfrentados pelos escritórios nacionais, incentivando os países a realizarem sua adesão (MESQUITA, 2016).

De acordo com a OMPI (2021, tradução nossa),

O Sistema Madrid é uma solução conveniente e econômica para registrar e gerenciar marcas registradas em todo o mundo. Registra-se um único aplicativo e pague um conjunto de taxas para solicitar proteção em até 120 países".

Por meio da adesão ao referido acordo, pessoas físicas ou jurídicas dos países-membros podem requerer o depósito de uma marca em seu país de origem e a extensão da proteção dela para outros países através de um único protocolo (BRUCH; AREAS; VIEIRA, 2019).

A adoção do Protocolo foi um ponto de virada na evolução e de sucesso do Sistema de Madrid, significativamente contribuindo para a sua expansão global de forma a atrair novos membros e proprietários de marcas registradas que pretendiam proteger suas marcas nos mercados globais. Demorou mais de um século sob a vigência do Acordo de Madri para a adesão crescer de quatro membros em 1892 para 25 membros em 1988, conforme pode ser observado na Figura 2. Durante a primeira metade do século XX, todos os membros de Madri estavam localizados na Europa, com exceção dos três seguintes países: Egito com adesão em 1952, Marrocos com adesão em 1917 e Vietnã com adesão em 1949. A adesão ao acordo permaneceu restrita principalmente à Europa, devido às marcas registradas em vigor nos países europeus em causa, o que refletiu diretamente na sua cultura e estágio de desenvolvimento. Naquela época, a marca da União Europeia (UE) não existia e a rápida globalização ainda não havia começado (WIPO, 2019). 
Figura 2 - Tendência do número de membros e países cobertos por Madri, 1892-2018

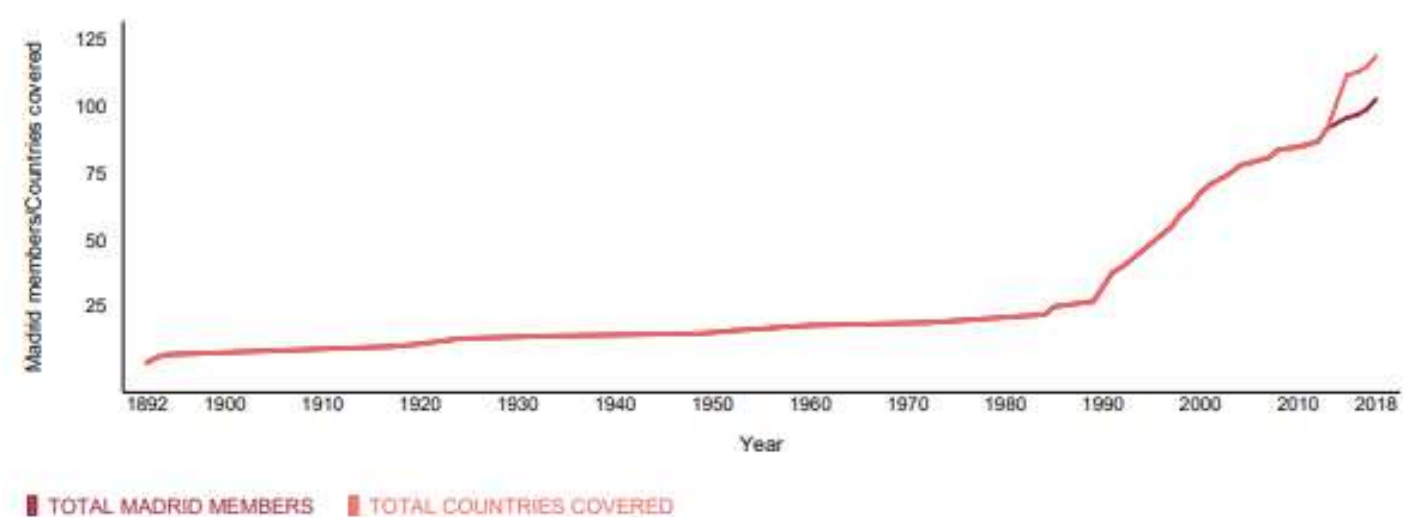

Fonte: WIPO (2019)

Desde a adoção do Protocolo, o Sistema de Madri expandiu seu escopo geográfico com a adição de 28 membros asiáticos, para citar alguns: a China, a Indonésia, o Japão, a República da Coreia e a Turquia; 25 membros europeus adicionais, predominantemente países do antigo bloco soviético e da União Europeia como um todo; 18 membros africanos, cobrindo um total de 34 países subsaarianos; quatro novos membros na América Latina e no Caribe (LAC) - Antígua e Barbuda, Colômbia, Cuba e México; três na Oceania - Austrália, Nova Zelândia e Samoa; e um na América do Norte - Estados Unidos da América (EUA) (WIPO, 2019).

A adição de novos membros ao Protocolo Madrid e dos países cobertos por suas jurisdições levou a uma maior diversidade em termos de grupos de renda. Por exemplo, em 2018, a maior participação era de países de renda média (45\%) de todos os países abrangidos pelo Sistema de Madrid, seguido por países de alta renda (36\%) e de baixa renda (19\%). De fato, os países de renda média começaram a superar em número os países de alta renda em 2013, o grupo de renda mais altamente representado dentro do Sistema de Madri. Além disso, percebe-se que a quota dos países de baixa renda de todos os países-membros de Madrid mais do que dobraram desde 2013 (WIPO, 2019).

As posições divergem em relação ao Protocolo de Madri. Aqueles que entendem que o Protocolo é vantajoso apontam como motivadores: a economia de tempo e de dinheiro, haja vista estar centralizado em um único ato; e não ser necessária a contratação de um advogado em cada um dos países nos quais se pretende realizar o registro, já que atos como prorrogação, alterações de nome, sede, cessão e transferência são centralizados, o que simplificaria o procedimento (DI BLASI, 2010).

Há ainda os que observam desvantagens no procedimento: os documentos relativos ao processo são escritos em poucos idiomas (francês se regido exclusivamente pelo Acordo de Madri, inglês, francês e espanhol se regido pelo Acordo e/ou Protocolo, sendo que o escritório de origem poderá limitar a opção do solicitante a apenas um ou dois dos idiomas, ou permitir que o titular escolha um dos três) (OMPI, 2018); o escritório nacional de propriedade industrial de cada país terá um prazo de 12 ou 18 meses para a recusa do registro internacional, sendo que, caso não haja análise dentro do período, o registro é automaticamente concedido; em caso de recusa da marca, o requerente deverá, contudo, contratar advogado para apresentação de recurso de acordo como previsto na legislação local e, caso a marca seja deferida, estará também sujeita ao processo administrativo de nulidade. Em ambas as circunstâncias significará dispêndio de quantias significativas, tanto nas taxas oficiais como nos honorários dos profissionais 
especializados; comenta-se também sobre o risco de colocar a soberania dos países-membros em dúvida, na medida em que a OMPI centraliza todo o procedimento impondo decisões em detrimento dos direitos das diferentes nações, podendo afrontar as Constituições (DI BLASI, 2010).

Em síntese, o procedimento para um registro de marca internacional via Protocolo de Madri ocorre nos seguintes termos (OMPI, 2018; DI BLASI, 2010; BRASIL, 2019):

a) No ato da realização do pedido de registro da marca junto ao escritório nacional, o requerente poderá assegurar a proteção de sua marca em outros países mediante a inscrição do pedido no cadastro da Secretaria Internacional da OMPI (artigo $2^{\circ}$, Protocolo de Madri).

b) O pedido internacional se dará por via de formulário próprio, o qual será conferido pela administração de origem se o pedido de registro nacional confere com o pedido de registro internacional. A Administração nacional ainda indicará o número do processo e a data de pedido ou registro na origem. No mesmo formulário, deverá constar os produtos e serviços para os quais a marca está sendo reivindicada, a classe ou classes correspondentes de acordo com a Classificação de Nice. Caso não haja a indicação de classe, a própria Secretaria internacional fará (artigo $3^{\circ}$, Protocolo de Madri).

c) O pedido internacional está sujeito ao pagamento de uma taxa base para um pedido de marca em até três classes; uma taxa suplementar por cada classe de produtos e serviços excedentes e uma taxa complementar por cada país escolhido para registro da marca internacional.

d) A Secretaria Internacional notificará a inscrição internacional aos países designados. As marcas inscritas serão publicadas na Gazeta da OMPI (artigo $3^{\circ}$, ponto 4, Protocolo de Madri).

e) Ao receber a notificação, o país designado poderá, por meio de notificação de recusa, declarar a impossibilidade de proteção da marca em seu território. Essa notificação deverá ser encaminhada à Secretaria Internacional no prazo de 12 meses contados da data da notificação do registro internacional, sendo possível dilatar o prazo até 18 meses (artigo $5^{\circ}$, alíneas "b" e "c", Protocolo de Madri).

f) Após obter a informação de recusa, o requerente do registro internacional poderá interpor os recursos cabíveis (artigo $5^{\circ}$, ponto 3, Protocolo de Madri).

g) O registro internacional permanecerá dependente do registro-base (de origem) pelo prazo de cinco anos, sendo que, se o pedido-base for retirado, indeferido, objeto de renúncia, anulação ou expiração, o registro internacional é anulado. Isso é chamado por Di Blasi (2010) de "ataque central" (artigo 6 , ponto 3, Protocolo de Madri).

h) Passados os cinco anos iniciais, o registro internacional se torna independente do pedido-base (artigo $6^{\circ}$, ponto 3, Protocolo de Madri).

i) A validade do registro internacional é de dez anos, podendo ser renovado por iguais e sucessivos períodos, mediante o pagamento das taxas respectivas (artigos $6^{\circ}$ e $7^{\circ}$ do Protocolo de Madri).

j) Na hipótese de o registro internacional ser anulado via ataque central, o titular terá três meses para efetivar os depósitos locais correspondentes à mesma marca, nos países que se achavam cobertos pelo registro internacional, beneficiando-se da data do registro in- 
ternacional ou de sua prioridade se houver, sujeitando-se às exigências de cada legislação e pagamento de taxas locais (artigo 9', Protocolo de Madri).

k) Em caso de denúncia ao Protocolo por algum membro, o titular do registro terá o prazo de dois anos para conversão do registro internacional em pedido local.

De forma geral, o Acordo e o Protocolo de Madri possuem o mesmo intuito: o de promover a globalização com o registro internacional de marcas efetivado mediante: a) uma solicitação; b) estar no território de origem (escritório nacional); c) pagar uma única taxa; e d) com um número de registro (TEIXEIRA, 2006). Contudo, o Protocolo veio na tentativa de resolver conflitos gerados por algumas características inerentes ao Acordo.

O Quadro 1 sintetiza as características inerentes ao Acordo de Madri (MESQUITA, 2016) e a "solução" trazida pelo Protocolo de Madri para cada uma.

Quadro 1 - Características do Acordo e do Protocolo de Madri

\begin{tabular}{|c|c|c|}
\hline & ACORDO DE MADRI & PROTOCOLO DE MADRI \\
\hline $\begin{array}{l}\text { Necessidade de } \\
\text { registro nacional }\end{array}$ & $\begin{array}{l}\text { Para que se possa ingressar com pedido } \\
\text { de registro de marca internacional } \\
\text { esta deverá estar registrada e vigente } \\
\text { perante o escritório nacional de } \\
\text { registro de marcas do país originário. } \\
\text { Problema: Países nos quais a marca } \\
\text { possui proteção independente da } \\
\text { concessão do registro não visualizavam } \\
\text { vantagens na adesão do acordo, bem } \\
\text { como aqueles que possuíam atraso } \\
\text { na análise dos processos de marca } \\
\text { se viam prejudicados com o risco } \\
\text { da perda de direito da prioridade } \\
\text { oferecida pela Convenção da União } \\
\text { de Paris frente aos países que possuem } \\
\text { maior celeridade no processo. }\end{array}$ & $\begin{array}{c}\text { De forma a resolver o problema apresentado } \\
\text { pelo Acordo, o Protocolo autoriza a } \\
\text { possibilidade de proteção internacional } \\
\text { com base apenas no processo de } \\
\text { registro, sem análise de mérito acerca do } \\
\text { deferimento e concessão do registro. }\end{array}$ \\
\hline Prazo de Recusa & $\begin{array}{l}\text { A administração local deverá } \\
\text { informar à Secretaria internacional } \\
\text { a recusa provisória ou definitiva } \\
\text { do processo de marca no prazo } \\
\text { máximo de } 12 \text { meses sob pena de } \\
\text { deferimento compulsório do registro. }\end{array}$ & $\begin{array}{l}\text { O prazo de } 12 \text { meses é aumentado se a } \\
\text { parte solicitar, de forma que a possibilidade } \\
\text { de recusa provisória deverá ser informada } \\
\text { dentro do prazo (fundamentada em } \\
\text { oposições) naqueles países que concedem } \\
\text { prazo para o referido incidente após a } \\
\text { análise de mérito para que não haja } \\
\text { perda de direito decisório sobre a } \\
\text { registrabilidade da marca e possam assim } \\
\text { aplicar após os } 18 \text { meses oferecidos. }\end{array}$ \\
\hline Ataque Central & $\begin{array}{l}\text { Durante os primeiros } 5 \text { anos de } \\
\text { vigência, o registro internacional } \\
\text { permanece dependente do pedido } \\
\text { ou registro originário, de forma que } \\
\text { se este for indeferido, expirado, } \\
\text { anulado, renunciado, revogado ou } \\
\text { invalidado, ainda que de forma } \\
\text { parcial, for objeto de demanda judicial } \\
\text { ou oposição, mesmo que a decisão } \\
\text { seja proferida após os cinco anos. }\end{array}$ & $\begin{array}{l}\text { O Protocolo de Madri permite que o titular } \\
\text { da marca transforme o registro internacional } \\
\text { em registro nacional em cada país } \\
\text { designado, mantendo a data da solicitação } \\
\text { internacional, desde que depositado } \\
\text { nacionalmente dentro de um período de três } \\
\text { meses, contado da data de anulação para } \\
\text { assegurar a anterioridade de registro no país. }\end{array}$ \\
\hline Idioma & $\begin{array}{l}\text { A língua oficial é o francês, } \\
\text { restringindo grande parte das } \\
\text { economias internacionalizadas. }\end{array}$ & $\begin{array}{l}\text { Buscando a harmonização e o aumento } \\
\text { da globalização o protocolo adiciona às } \\
\text { línguas oficiais o inglês e o espanhol. }\end{array}$ \\
\hline
\end{tabular}




\begin{tabular}{|c|c|c|}
\hline & ACORDO DE MADRI & PROTOCOLO DE MADRI \\
\hline $\begin{array}{c}\text { Inclusão de } \\
\text { Organizações } \\
\text { Intergovernamentais }\end{array}$ & $\begin{array}{l}\text { Somente nações individuais } \\
\text { poderiam aderir como membros e } \\
\text { usufruir da proteção internacional } \\
\text { de marcas para seus nacionais. }\end{array}$ & $\begin{array}{l}\text { Inclui a possibilidade de Organizações } \\
\text { intergovernamentais aderirem desde que: } \\
\text { i) pelo menos um dos estados membros } \\
\text { deve ser parte da Convenção de Paris para } \\
\text { proteção da propriedade intelectual; ii) a } \\
\text { organização deve ter uma administração } \\
\text { encarregada de registrar as marcas que } \\
\text { produzam efeitos no território de origem. }\end{array}$ \\
\hline $\begin{array}{l}\text { Vigência do Registro } \\
\text { Internacional }\end{array}$ & $\begin{array}{l}\text { A vigência de uma marca } \\
\text { internacional é de } 20 \text { anos contados } \\
\text { da data do pedido de registro } \\
\text { à secretaria internacional. }\end{array}$ & $\begin{array}{l}\text { Procurou uniformizar o período de vigência } \\
\text { para } 10 \text { anos, de acordo com o período de } \\
\text { vigência oferecido pela maioria dos países. }\end{array}$ \\
\hline $\begin{array}{l}\text { Pagamento } \\
\text { das Taxas }\end{array}$ & $\begin{array}{l}\text { Requer o pagamento de uma taxa } \\
\text { base, taxa suplementar para cada } \\
\text { classe a partir da terceira e taxa } \\
\text { complementar por cada pedido de } \\
\text { extensão territorial de proteção da } \\
\text { marca, permitindo ainda aos países } \\
\text { a cobrança de taxa nacional em } \\
\text { benefício próprio, concomitante as } \\
\text { taxas da secretaria internacional. Os } \\
\text { valores são distribuídos entre os países } \\
\text { membros de forma proporcional com } \\
\text { a atuação de cada escritório nacional. }\end{array}$ & $\begin{array}{c}\text { É facultado aos países signatários a qualquer } \\
\text { tempo declarar a opção de recebimento } \\
\text { de receitas provenientes das taxas } \\
\text { suplementares e complementares rateadas } \\
\text { proporcionalmente, ou solicitar que o titular } \\
\text { da marca internacional efetive o pagamento } \\
\text { de uma taxa individual para o registro ou } \\
\text { renovação da marca. A taxa individual, } \\
\text { contudo, não poderá ser superior à devida } \\
\text { ao escritório nacional para fins de registro e } \\
\text { renovação nacional. A declaração não isenta } \\
\text { os países de receberem valores anualmente } \\
\text { partilhados provenientes de receitas } \\
\text { criadas pelo registro internacional depois } \\
\text { de descontadas as despesas e encargos } \\
\text { resultantes da aplicação do Protocolo. }\end{array}$ \\
\hline
\end{tabular}

Fonte: Elaborado pelos autores deste artigo (2019)

\subsection{Adesão do Brasil ao Protocolo de Madri}

Uma vez que o Brasil firmou o Protocolo, o país internalizou ele no seu sistema de Leis, tornando suas novas disposições operacionais pelo INPI para que se dê início aos seus efeitos práticos, alterando o sistema atual de marcas. E para que a operação iniciasse de forma tranquila, no mês de maio de 2019, o INPI publicou quatro consultas públicas, cada uma apresentando uma proposta de resolução, com fins de colher críticas e sugestões do público sobre o Protocolo de Madrid. O objetivo do INPI era adaptar a Autarquia Federal para que os novos pedidos de registro que pretendessem utilizar o Sistema de Madri fossem realizados em um procedimento devidamente adaptado para tanto, já que o sistema da época não era inteiramente compatível com o Sistema de Madri.

As quatro propostas tratavam do sistema de registro multiclasse, da divisão de um registro (ou pedido), da cotitularidade de um registro (ou pedido), e das regras gerais de uso do Sistema de Madri para o registro internacional de marcas. Em julho de 2019, o Brasil depositou perante a OMPI o instrumento de adesão ao protocolo, e a ratificação ao acordo veio com a Resolução n. 247/2019 (INPI, 2019) e, em 2 de outubro de 2019, houve a publicação do Decreto n. 10.033/2019, que promulgou o Tratado. Porém, depois de um ano da entrada em vigor do Protocolo, ainda não se conseguiu implementar no país algumas das previsões originalmente contidas no Tratado. 


\subsection{O Sistema de Classes, a Novidade Multiclasse e o Sistema de Classificação Brasileiro}

O sistema de marcas é complexo e conta com vários tipos de classificações para organizá-lo. Uma dessas classificações é a de atividades de mercado que serão desenvolvidas com emprego da marca que se pretende registrar, o que se revela importante, haja vista que uma marca é o conjunto de uma apresentação (como a marca se apresenta ao seu público destinatário) e uma especificação (para qual mercado a marca se destinará).

Esse sistema de classificação por atividades possibilita que uma mesma apresentação possa ser utilizada em mais de um mercado, sem que haja possibilidade de confusão. A classificação das marcas é o que propicia que marcas com uma mesma apresentação, mas destinadas para mercados distintos, possam conviver. Isso se verifica quando se vê no mercado a VEJA e um produto de limpeza VEJA, ambas as marcas com a mesma apresentação (VEJA), mas cada uma de propriedade de um titular distinto e para ser explorada em um mercado distinto.

$\mathrm{Na}$ história recente, o Brasil adotou um classificador nacional que era dividido em 41 classes, com itens e subitens. Esse sistema foi utilizado até a disposição do Ato Normativo $\mathrm{n}$. 150/99 do INPI, que dispôs sobre a utilização de um sistema de classificação internacional de produtos e serviços, considerando valores como modernidade, eficácia, necessidade de estar atualizado, e uma necessidade de adequar a classificação adotada no Brasil com aquela que à época era adotada internacionalmente, "[...] em virtude do processo de globalização da economia" (INPI, 1999).

Foi a partir de 3 de janeiro de 2000 que o Brasil iniciou o uso da classificação de atividades, instituída pelo Tratado de Nice, porém, o que importa para o presente trabalho é o que tal ato resolveu em seu ponto 2: "[...] que cada pedido de registro deverá assinalar uma única classe, e conter, obrigatoriamente, a especificação dos produtos e serviços identificados pela Classificação Internacional de Produtos e Serviços" (INPI, 1999). O classificador foi atualizado internacionalmente em mais de uma ocasião, mas até o presente momento, mesmo com a entrada em vigor do Protocolo de Madri, o sistema brasileiro não permite que um pedido de registro seja realizado em mais de uma classe.

A classificação instituída pelo Tratado de Nice possui 45 classes de atividades, sendo 34 classes de produtos e 11 classes de serviços, não sendo um rol exaustivo, em face das constantes novidades de mercado: novos produtos e novos serviços oferecidos ao público. Como qualquer classificador, existem atividades que se situam na fronteira dos limites estabelecidos como parte de uma classe, não sendo possível fazer o pedido de uma marca contendo especificações de uma classe para registro em classe diversa. Com isso, o requerente do pedido de registro se encontra, muitas vezes, com a necessidade de fazer mais de um pedido de registro para obter uma proteção plena de suas atividades realizadas sob a apresentação da marca pretendida.

Ao contrário do Brasil, outros países adotaram um sistema diferenciado, multiclasse, que permite ao requerente pedir especificações contidas em mais de uma classe, tornando o sistema menos burocrático (diminuindo o número de requerimentos) e menos oneroso (diminuindo as despesas de requerimento e manutenção do registro). E, ao ingressar no sistema de Madri, o Brasil estaria adequado a essa realidade, ou pelo menos deveria. 


\subsection{O Sistema Multiclasse de Madri}

Passados 20 anos da disposição do Ato Normativo n. 150/99, o Brasil avançou mais um passo em busca de estar adequado ao processo da globalização: ingressou no Sistema de Madri e deveria ter modificado seu sistema de classes, permitindo um pedido de registro multiclasse, conforme disposto na consulta pública realizada pelo INPI em maio de 2019. Uma vez requerido um pedido de registro multiclasse, o INPI realizaria o exame separadamente em cada classe, o que significa que um pedido com duas classes teria dois exames, $e$ um pedido com três classes teria três exames.

Em havendo mais de um exame, a decisão poderia ser de deferimento, indeferimento, ou ainda deferimento parcial: o INPI entenderia que uma classe deve ser deferida e outra deve ser indeferida. Há outro tema que requer atenção do usuário do sistema de marcas, pois, em caso de deferimento parcial, o titular poderia (ou deveria, a depender de seus interesses) tomar duas ações: pagar as taxas de expedição do certificado de registro das classes que foram deferidas $e$ recorrer das decisões de indeferimento nas demais classes. Se não recorresse, a decisão de indeferimento se tornaria definitiva, sendo a marca registrada apenas para as classes e atividades que foram deferidas pelo INPI. Mas se o titular recorresse e não pagasse as taxas de expedição do certificado de registro das classes deferidas, todo o seu pedido seria arquivado - o que significa, tornado sem efeitos.

Resumidamente, o sistema multiclasse apresenta inicialmente dois pontos relevantes para formação da estratégia de opção pelo sistema: a) estudo sobre a possibilidade de sobrestamento do exame de uma das classes requeridas, sob pena de atrasar o exame das demais classes (que não estariam sofrendo com o sobrestamento se requeridas em separado); b) necessidade de recolhimento das taxas de deferimento de todas as classes deferidas, quando há deferimento parcial e interesse no recurso ao indeferimento das demais classes.

Outros dois temas importantes para o presente estudo são a transferência do registro (ou pedido de registro) multiclasse para outro titular e, decorrente deste, a possibilidade de divisão do pedido multiclasse para classes singulares. Justifica-se: um dos direitos do titular de um registro de marca é o de ceder a marca para terceiros (o que tecnicamente significa vender a marca). Muitas empresas têm mais de um registro de marca para proteger uma mesma apresentação, cada registro em uma classe distinta, para uma atividade distinta. Se esta empresa opta por vender parte de sua operação, pode ceder junto sua marca, agregando valor ao negócio. No sistema multiclasse, a marca requerida possui muitas atividades conjuntas, $e$, talvez, não seja do interesse do titular ceder todas as classes, mas apenas uma. Como realizar o negócio nesse caso? Esse questionamento revela uma dificuldade prática que as pessoas optantes iriam encontrar no sistema multiclasse.

É ainda relevante relembrar o que já introduzimos, que uma marca serve para identificar um produto ou serviço de outro de origem diversa, devendo ser ela um indicador que individualiza o produto ou serviço, distinguindo-os dos demais no mercado. É por isso que, ao transferir uma marca, o INPI examina se o cedente (vendedor) possui outras marcas com apresentação semelhantes, especificações idênticas, ou afins àquelas da marca transferida. Qualquer registro ou pedido com essas características, que remanescem na propriedade do cedente, será cancelado de ofício pelo INPI. Esse é um fator que torna complexa a cessão de uma marca multiclasse. 
E como último fator de complexidade em caso de transferências há a necessidade do cessionário da marca (o comprador) ter legitimidade para ter a propriedade da marca, o que significa dizer que ele tenha a possibilidade jurídica de usar a marca. Isso pode ser visto nos seus atos constitutivos (no caso de pessoas jurídicas), ou por meio de comprovantes de formação profissional (no caso de pessoas físicas). Lista-se, então, um último ponto que nos parece relevante ser avaliado no momento do requerimento do pedido de registro de marca: c) o requerente deve avaliar a conveniência de se agregar as classes de marcas em uma só, reduzindo burocracia no momento do registro para encontrar burocracia no momento de negociar parte desse registro no futuro. Sendo esses os problemas encontrados na proposta de marco resolutivo do INPI, é importante verificar quais as soluções que foram propostas pela Autarquia Federal.

\subsection{A Possibilidade de Divisão de um Registro (ou pedido de registro) Multiclasse como Forma de Solução para os Problemas Encontrados}

Para solucionar parte dos problemas encontrados com o sistema multiclasse, o INPI propôs resolver procedimentos de divisão de registros (e pedidos de registro). A primeira hipótese proposta é o caso de sobrestamento do pedido de registro multiclasse, para que o requerente possa separar as demais classes daquela que está com um impedimento para a realização do exame. Com isso, o problema "a" encontrado acima estaria solucionado. Nesse caso, a divisão daria origem a um novo pedido que seria submetido para o exame.

A segunda hipótese proposta pelo INPI é a divisão para fins de transferência de titularidade, que poderia dividir o registro em classes e até mesmo produtos ou serviços, caso estes estejam na mesma classe, mas, entre si, não sejam idênticos, semelhantes ou guardem afinidade. Esse ponto ajuda a resolver o problema "c" apontado acima, mas não por completo. Ainda assim é necessário um procedimento burocrático no momento da cessão, o que diminui o valor do bem negociado - tal como qualquer outro fator complicador, que, nesse caso, é mais grave pelo fato de o INPI levar meses para decidir se defere ou não defere a transferência, bem como pela própria incerteza do resultado da decisão. Ou seja, há solução, mas ela consome tempo e projeta insegurança.

\subsection{Do Sistema de Cotitularidade}

Um tema objeto de discussão há anos é a contradição entre a possibilidade de uma marca, que tem como objetivo determinar uma origem própria e definida de um produto ou serviço de ter mais de um dono. Na década de 1980, Fletcher (1982) explicava o desafio da cotitularidade, no qual se encontravam dificuldades perante o United States Patent and Trademark Office (USPTO), que em reiteradas decisões declarou que a função de uma marca registrada é indicar a singeleza da fonte comercial, ou seja, uma origem definida. Quando há o compartilhamento da propriedade da marca, essa função principal da marca pode ser esvaziada, perdendo sentido a própria existência da marca.

Uma fração das transferências de registros de marca realizadas no INPI são feitas entre empresas e pessoas do mesmo grupo econômico, para fins de gestão patrimonial. Logo, uma fração dos problemas listados anteriormente poderia ser resolvida por meio do instituto da 
cotitularidade. É formado um condomínio da marca, em que mais de uma pessoa, física ou jurídica, é proprietária da marca, o que até o advento do Protocolo de Madri não era permitido.

Nesse sistema de cotitularidade se possibilita que haja mais de um titular, desde que todos os titulares exerçam de forma efetiva e lícita as atividades especificadas no registro da marca, de forma direta ou indireta. Isso ocorre com empresas do mesmo grupo econômico, mas também possibilita a união de esforços de mais de uma pessoa em torno de um objetivo, por exemplo, em uma joint venture, na qual possam ser identificadas com uma marca, sendo esta marca propriedade de todos os participantes.

Sendo essas algumas das vantagens, podem ser encontradas também algumas desvantagens. A resolução do INPI dispõe que os atos das partes devem ser praticados por todos os titulares, de forma conjunta, o que torna o processo mais complexo. Isso significa dizer que é necessário acordo de vontades, organização entre as partes, disponibilidade para firmar documentos nos momentos apropriados, entre outros temas. Algumas pessoas jurídicas possuem regras próprias para a firmatura de documentos, muitas vezes demandando que, em determinados casos, duas ou três pessoas específicas devem assinar documentos para ter validade. Multiplique isso por duas ou três empresas e se terá um grande grupo de pessoas das quais a marca depende para ser impulsionada.

Outro fator de complexidade é que, muitas vezes, nem todos os cotitulares têm pretensões de atuação no estrangeiro. Mesmo assim, para exercer os direitos de prioridade, todos devem ser requerentes dos pedidos no exterior, ou deve-se operar cessão de direitos. Em um cenário de harmonia negocial, não se enfrentaria essas dificuldades, mas uma cotitularidade de pedido de registro em outra situação pode causar danos irreversíveis para seus titulares, como a perda de uma prioridade por ausência de entendimento e assinatura dos documentos necessários por todas as empresas.

Há um fator interessante que poderá ser utilizado pelas empresas que hoje se valem de acordos de convivência, e agora poderão celebrar condomínios de registro de marca, por meio de contrato próprio e pedido de registro em cotitularidade para cada uma das variações de marca que essas empresas pretendem utilizar.

É importante destacar que o INPI pretende ver o grupo de cotitulares como uma nova individualidade, distinta dos indivíduos que compõem o condomínio da marca. Ou seja, pode haver conflito entre uma marca de titularidade de apenas um cotitular, com a marca a ser registrada em cotitularidade. Ou ainda, quando o conjunto de titulares não é idêntico àquele conjunto de titulares de um registro conflitante e anteriormente registrado.

Uma vantagem desse sistema é que, em caso de pedido de caducidade do registro, pelo não uso, a prova de uso por qualquer dos cotitulares é aproveitada para todos, mas, em caso de alegação de justa causa pelo não uso, essa prova deverá afetar a todos os titulares. De maneira que, mesmo que um titular tenha justa causa pelo não uso da marca, se os demais não utilizaram a marca, ela será declarada caduca e o registro extinto pelo INPI.

Por fim, toda a transferência de direitos somente poderá ser realizada com a assinatura de todos os cotitulares ou requerentes, o que aumenta a dependência dos cotitulares entre si e diminui a autonomia dos indivíduos sobre sua fração da marca. Pode-se então listar alguns problemas encontrados com o regime da cotitularidade, conforme proposto pelo INPI nos textos submetidos para consulta pública: a) dependência extrema dos cotitulares entre si; b) diminuição 
da autonomia da vontade de cada titular, quanto à disposição de seu patrimônio marcário; c) formalidade excessiva para cumprimento de atos no INPI, dependendo da assinatura e vontade de todos os cotitulares; d) dificuldade na alegação de justa causa em caso de pedido de caducidade do registro;

Nesse cenário, como não há uma proposição de solução por parte do INPI para os temas acima, recomenda-se que a formação de um condomínio de proprietários de um registro de marca inicie com um contrato que tenha a disposição sobre esses temas, por meio da constituição de procurador único que represente todos os interessados, e com regras que tornem simples a disposição das frações ideais de cada um dos cotitulares sobre os direitos sobre o pedido de registro e, posteriormente, sobre a propriedade do registro da marca.

\subsection{Da Proteção Internacional e dos Idiomas Eleitos}

Uma vez adaptado o sistema nacional para o de Madri, ainda que parcialmente, o INPI possibilitou resolver também o tratamento internacional dos pedidos de registro. Isso porque sempre houve uma necessidade de se receber pedidos advindos do exterior, e realizar pedidos do Brasil para o exterior, tudo dentro de um sistema harmônico.

Após uma série de definições, o INPI fez a eleição dos idiomas dos pedidos internacionais, determinando que pedidos, petições e comunicações deverão ser redigidos em inglês ou espanhol. Deve ficar claro para o requerente da marca que o idioma oficial do Brasil, a Língua Portuguesa, não é aceito para uso no sistema. Um segundo ponto importante é a dupla limitação para requerer um registro internacional pelo INPI: a pessoa deve ser nacional do Brasil e ter domicílio ou estabelecimento no país. O estrangeiro e o brasileiro, sem um local determinado no país, não podem fazer uso do sistema de Madri por meio do INPI.

\subsection{Da Vinculação do Pedido Internacional ao Pedido Nacional (Pedido- Base) e da Situação dos Pedidos Nacionais Frente aos Pedidos Estrangeiros Realizados no Brasil por meio do Sistema de Madri}

O Sistema de Madri tem como um de seus objetivos facilitar a obtenção do registro das marcas e a administração desses registros (OMPI, 2018). Há um pedido-base, original, a ser realizado no Brasil e, posteriormente, encaminhado para uma Secretaria Internacional, e processado para fins de internacionalização do registro.

Se, por um lado, o sistema facilita o pedido e a administração desse pedido em um procedimento internacional, de outro lado, ele cria uma vinculação entre todos os pedidos e o pedido-base por um período de cinco anos, contados desde a data da inscrição internacional do pedido.

O Decreto n. 10.033/2019 que internalizou o Protocolo previu que, em uma série de hipóteses, os pedidos internacionais podem ser cancelados, se o pedido-base, realizado no Brasil, for arquivado, indeferido, extinto, anulado ou cancelado. Dessa forma, um eventual problema ocorrido no Brasil tem impacto em todo o investimento realizado na internacionalização da marca, o que revela a importância da estratégia inicial do pedido-base e do cuidado com esse pedido, principalmente durante os primeiros cinco anos. 
Apesar de os idiomas oficiais do Sistema de Madri serem o francês, o inglês e o espanhol, o INPI, por meio da Resolução n. 247/2019 previu a necessidade de o pedido advindo do estrangeiro acompanhar tradução simples para o português, não afastando a necessidade do requerente estrangeiro manter um procurador com domicílio no Brasil (artigo 15) - o que evita procedimentos internacionais para discutir qualquer tema de marcas de titulares estrangeiros fora do Brasil.

Um ponto importante é que o INPI terá um prazo de 18 meses para tomar uma decisão final (artigo 20), salvo se houver algum fato processual que o impeça, devendo no mesmo prazo comunicar o fato para a Secretaria Internacional. E se o INPI não observar tal prazo, os pedidos nacionais do Brasil sofrerão com a concessão automática do pedido do estrangeiro (artigo 20, $\S 4^{\circ}$ ). Isso significa dizer que, em sendo automática, a concessão se dará independentemente de exame, podendo dar exclusividade de sinal de uso comum para um estrangeiro, ou ainda, de marca que conflite com outra anteriormente registrada.

Durante o período em que houve a consulta pública sobre o sistema, o INPI recebeu diversas manifestações positivas aparentando existir uma grande demanda reprimida do empresariado brasileiro interessado em desbravar o mercado externo. Contudo, depois de mais de um ano de vigência do Protocolo, a aparente demanda não se confirmou em números, já que os pedidos de registro via Protocolo efetivados por nacionais permanecem bem abaixo dos pedidos recebidos de estrangeiros designando o Brasil como país de interesse para exploração de suas marcas. Importante salientar que, até o presente momento, ainda não há previsão para funcionamento do sistema multiclasse, cotitularidade e divisão de pedidos/registros.

\section{Considerações Finais}

Tal como disse o ex-presidente do INPI, José Graça Aranha, nas suas considerações iniciais do Ato Normativo n. 150/99, a adesão do Brasil ao Protocolo de Madri se revela como mais um passo em direção à globalização da economia. Compreende-se que agiu certo o INPI ao lançar consulta pública sobre temas que representavam uma alteração significativa no processo de registro de marca brasileiro e nas possibilidades de registro internacional para os brasileiros aqui estabelecidos. Foi importante permitir que se faça uma análise crítica das alterações, e importante também para os administrados iniciarem os preparativos para o que estava por vir.

Algumas alterações facilitam procedimentos e controles iniciais, mas burocratizam situações futuras, tornando complexos alguns negócios que estão por ser celebrados nos próximos anos. Como visto, algumas lacunas restam pendentes de serem preenchidas com soluções, como os valores das taxas para resolver a burocracia imposta na divisão de registros multiclasse e no cumprimento de atos em cotitularidade. Talvez, por isso, tais alterações ainda não tenham entrado em funcionamento. Ademais, sugere-se que o INPI estude a possibilidade de averbação de contratos de condomínio de marcas, cotitularidade de marcas, ou qualquer outra nomenclatura que se julgue mais adequada, como forma de solucionar parte da complexidade do sistema de cotitularidade e da necessidade de atuação de todas as partes nos atos processuais perante o INPI.

É preciso ter consciência da necessidade de analisar cada projeto marcário e de aproveitar as modificações instituídas pela adesão ao Protocolo de Madri, já consciente dos seus ônus 
e bônus, riscos e oportunidades. Em não o fazendo, é possível que o sistema instituído não alcance seus objetivos de facilitar o registro e sua manutenção, mas sim cause perda de valor de negócios e perda de posições marcarias no Brasil e no exterior. Por fim, é importante que o INPI institua um sistema de controle de prazos rigoroso, uma controladoria que evite que marcas sejam concedidas automaticamente para estrangeiros no Brasil, apenas por conta da sua morosidade.

\section{Perspectivas Futuras}

Espera-se que este artigo contribua com a discussão sobre a utilização do Protocolo de Madri para pedido e registro de marcas internacionais no Brasil, além da premente necessidade de funcionamento do sistema multiclasse, da cotitularidade e da divisão de pedidos de registros e registros, ainda pendentes de aplicação.

É preciso que o INPI, assim como aqueles que utilizarão o Sistema de Madri, esteja a par dos benefícios e malefícios do Sistema os quais este trabalho pretende elucidar. Ao promover a discussão sobre o sistema multiclasse, cotitularidade e divisão de pedidos, este artigo também poderá contribuir para a discussão sobre os próximos passos que o INPI deverá tomar para tornar eficaz a aplicação do Sistema de Madri no Brasil.

\section{Referências}

ARRABAL, Alejandro Knaesel; COLOMBO, Ana Paula. A marca e sua Registrabilidade no Direito Brasileiro. In: SANTOS, Wagna Piler Carvalho dos (org.). Conceitos e aplicações de propriedade intelectual. Salvador: IFBA, 2018. v.1, p. 147-194.

BARBOSA, Pedro Marcos Nunes. Internalização do Protocolo de Madri e as vicissitudes jurídicas perante o ordenamento nacional. Revista da Associação Brasileira de Propriedade Intelectual, Rio de Janeiro, n. 156, set.-out. 2018.

BRASIL. Decreto n. 5.685, de 30 de julho de 1929. Approva a Convenção de Paris e os Accordos de Madrid. Rio de Janeiro: Presidência da República. Disponível em: https://www2.camara. leg.br/legin/fed/decret/1920-1929/decreto-5685-30-julho-1929-561787-publicacaooriginal-85514-pl. html. Acesso em: 8 jun. 2019.

BRASIL. Decreto n. 196, de $\mathbf{1}^{\circ}$ de dezembro de 1934. Promulga a denuncia do accôrdo relativo ao registro internacional das marcas de fabrica ou de commercio, assignado em Madrid, a 14 de abril, de 1891, e revisio, pela última vez, na Haya, a 6 de novembro de 1925. Rio de Janeiro: Presidência da República. Disponível em: https:/www2.camara.leg.br/legin/ fed/decret/1930-1939/decreto-196-31-dezembro-1934-556740-republicacao-77000-pe.html. Acesso em: 9 jun. 2019.

BRASIL. Decreto n. 10.033, de $\mathbf{1}^{\circ}$ de outubro de 2019. Promulga o Protocolo referente ao Acordo de Madri sobre o Registro Internacional de Marcas, firmado em Madri, Espanha, em 27 de junho de 1989, o Regulamento Comum do Acordo de Madri relativo ao Registro Internacional de Marcas e do Protocolo referente ao Acordo e a formulação das declarações e notificações que especifica. Brasília: Presidência da República, 2019. Disponível em: http://www.planalto.gov.br/ ccivil_03/_ato2019-2022/2019/decreto/D10033.htm. Acesso em: 15 mar. 2021. 
BRUCH, Kelly Lissandra; COPETTI, Michele. Evolução das indicações geográficas no direito brasileiro. Revista Brasileira de Viticultura e Enologia, Bento Gonçalves, ano 2, n. 2, p. 15-24, 2010. Disponivel em: https://www.enologia.org.br/default/uploads/revista/revista-34.pdf?34093029a7 68b7fd809a0d3db86e7b74. Acesso em: 9 jun. 2019.

BRUCH, Kelly Lissandra; AREAS, Patrícia de Oliveira; VIEIRA, Adriana Carvalho Pinto.Acordos internacionais relacionados à propriedade intelectual. In: SANTOS, Wagna Piler Carvalho dos (org.). Conceitos e aplicações de propriedade intelectual. Salvador: IFBA, 2019. v. 2, p. 59-208.

COPPETI, Michele. Direito de Marcas: a afinidade como exceção ao princípio da especialidade. 2008. 196p. Dissertação (Mestrado em Direito) - Centro de Ciências Jurídicas, Universidade Federal de Santa Catarina, Florianópolis, 2008. Disponível em: http://repositorio.ufsc.br/xmlui/ handle/123456789/91938. Acesso em: 11 jun. 2019.

DI BLASI, Gabriel. A propriedade industrial: os sistemas de marcas, patentes, desenhos industriais e transferência de tecnologia. Rio de Janeiro: Forense, 2010.

FLETCHER, Patricia K. Joint Registration of Trademarks and the Economic Value of a Trademark System. University of Miami Law Review, Miami, v. 36, n. 2, p. 297-335, 1982. Disponível em: https://repository.law.miami.edu/umlr/vol36/iss2/5. Acesso em: 11 jun. 2019.

INPI - INSTITUTO NACIONAL DA PROPRIEDADE INDUSTRIAL. Ato Normativo n. 150, de 9 de setembro de 1999. Dispõe sobre a adoção da Classificação Internacional de Produtos e Serviços e dá outras providências. Rio de Janeiro: INPI, 1999. Disponível em: https://www.wipo.int/ edocs/lexdocs/laws/pt/br/br124pt.pdf. Acesso em: 6 jun. 2019.

INPI - INSTITUTO NACIONAL DA PROPRIEDADE INDUSTRIAL. Resolução n. 247, de 9 de setembro de 2019. Dispõe sobre o registro de marca no âmbito do Protocolo de Madri. Rio de Janeiro: INPI, 2019. Disponível em: https:/www.gov.br/inpi/pt-br/backup/centrais-de-conteudo/ legislacao/Resoluo2472019.pdf. Acesso em: 6 jun. 2019.

MESQUITA, Paula Andrea Roese. Análise da aplicação do protocolo de Madri para proteção internacional de marcas no Brasil. 2016. 40p. Trabalho de Conclusão de Curso (Especialização em Direito) - Faculdade de Direito, Universidade Federal do Rio Grande do Sul, Porto Alegre, 2016. Disponível em: https://lume.ufrgs.br/handle/10183/150953. Acesso em: 14 jun. 2019.

OMPI - ORGANIZAÇÃO MUNDIAL DA PROPRIEDADE INTELECTUAL. O Acordo de Madrid relativo ao registro internacional de marcas e o Protocolo referente a este Acordo: objetivos, principais características, vantagens. 2018. Disponível em: http:/www.wipo.int/edocs/pubdocs/pt/ marks/418/wipo_pub_418.pdf>. Acesso em: 8 jun. 2019.

OMPI - ORGANIZAÇÃO MUNDIAL DA PROPRIEDADE INTELECTUAL. Madrid: The International Trademark System. 2021. Disponível em: https://www.wipo.int/madrid/en/. Acesso em: 20 mar. 2021.

TEIXEIRA, Cassiano Golos. Proteção Internacional de Marcas. Revista Brasileira de Direito Internacional, Curitiba, v. 4, n. 4, p. 278-294, jul.-dez. 2006. Disponível em: http://dx.doi. org/10.5380/rbdi.v4i4.7335. Acesso em: 9 jun. 2019.

WIPO - WORLD INTELLECTUAL PROPERTY ORGANIZATION. Madrid Yearly Review 2019: International Registration of Marks. Genebra: WIPO, 2019. Disponivel em: https:/www.wipo.int/ edocs/pubdocs/en/wipo_pub_940_2019.pdf. Acesso em: 16 jun. 2019. 


\section{Sobre os Autores}

\section{Vanessa Pereira Oliveira Soares}

E-mail: vanessa.oliveira@cesarperes.com.br ORCID: http://orcid.org/0000-0001-9416-0790

Especialista em Direito de Propriedade Intelectual pela FADERGS em 2014. Mestranda em Propriedade Intelectual e Transferência de Tecnologia para Inovação (PROFNIT), Ponto Focal IFRS, Porto Alegre (2019).

Endereço profissional: Rua Dom Pedro II, n. 568, São João, Porto Alegre, RS. CEP: 90550-140.

\section{Ricardo Sant'Anna Ramalho}

E-mail: ricardo@pap.com.br

ORCID: https://orcid.org/0000-0002-7386-9765

Especialista em Direito Público pela ESVJ em 2019. Mestrando em Propriedade Intelectual e Transferência de Tecnologia para Inovação (PROFNIT), Ponto Focal IFRS, Porto Alegre (2019).

Endereço profissional: Largo Visconde do Cairú, n. 17, 5 andar, Centro Histórico, Porto Alegre, RS. CEP: 90030-110.

\section{Genizia Islabão de Islabão}

E-mail: genizia.islabao@gmail.com

ORCID: https://orcid.org/0000-0002-0866-5766

Doutora em Química pela IME em 2011.

Endereço profissional: Av. Ipiranga, n. 6.681, Partenon, Porto Alegre, RS. CEP: 90619-900. 